\title{
ENVIRONMENTAL FORENSICS
}

\section{ENVIRONMENTAL FORENSICS: THE WHAT? WHEN? WHERE? WHY? AND HOW?}

The term "environmental forensics" has been in explicit use in scientific literature since 1994. McGee and Block (1994) - the earliest article noticed in literature to use the term "environmental forensics" - discussed the failure of environmental forensics to emerge as a discipline. Rusk (1996) presented environmental forensics as a mechanism for technical support to complex, controversial and high stakes environmental litigation. The emergence of environmental forensics as an important area of study can be attributed to the Comprehensive Environmental Response, Compensation and Liability Act (CERCLA) or Superfund legislation of the United States of America that made the polluters pay for their role in pollution since the 80's (Varghese and Alappat, 2012). Identifying the source(s) of pollution and providing a technical framework for allocating the responsibility among the polluter(s) using scientific methods were understood to be the fundamental purposes of the field of environmental forensics in the initial years of the field's evolution.

But pollution crimes, such as the illegal emission or discharge of substances into air, water or soil, form only a part of the larger spectrum of environmental crimes, including, for example: the illegal trade in wildlife, illegal trade in ozone-depleting substances, illegal transport, shipment or dumping of waste.

INTERPOL has identified environmental crime as a growing international crime area having an extremely detrimental impact on the planet, biodiversity, the global economy and human life. A 2016 INTERPOL report estimates the position of environmental crime as the fourth largest crime in the world (91-258 billion USD) after drug trafficking (344 billion USD), counterfeit crimes (288 billion USD) and human trafficking (157 billion USD), by value (Nellemann et al., 2016). This calls for extensive use of science and technology in combating environmental crimes, yet this type of crime is commonly overlooked in terms of investment. Environmental forensics, being the area primarily looked upon for technical solutions to environmental crimes, needs to widen its scope to address the expanding realm of environmental crimes. Further, there is a need to foster more research in the area of environmental forensics to respond to the evolving challenges.

Given the requirement of expanding its scope, there is a need to modify the traditional definition of environmental forensics, which primarily addressed pollution crimes. In the new context environmental forensics may be defined as "a multidisciplinary science which aims to apply scien- tific methods and knowledge to the diverse range of environmental concerns in the context of a regulatory and legal framework". This definition goes beyond the identification of the source and age of a contaminant which has been used to describe environmental forensics in the past (Morrison and Murphy, 2005).

Despite the importance of the subject, to the knowledge of the authors only one indexed journal, "Environmental Forensics" published by Taylor \& Francis, exists in this field. There is an urgent need to augment the publication avenues in the field of environmental forensics, which the 'Detritus Journal' plans to meet, at least partially. With reference to the aims of Detritus Journal, the following topics will be included: illegal waste trafficking, illegal landfills, misclassified waste streams, release of contaminants in terror threats, oil spill identification, crime scene investigation techniques, detection and identification of particular contaminants, wildlife crime, emerging pollutants and the methods for their detection, the role of the public in environmental forensics, case studies, historical environmental crimes and, the fate \& transport of pollutants.

Finally, from a scientific point of view, it is worth mentioning the parallelism between the scientific approach and the forensic approach graphically represented in Figure 1. In the latter, the phase of the experiment designing is replaced by the use of the well known "Six W's of Investigation" (what, where, who, when, why and how).

As an example, we can refer to a pollution crime represented by an uncontrolled leachate leakage from an old landfill. As environmental technical experts, we can apply an investigation approach that schematically includes a modelling phase of the transport of leachate from the source to the groundwater and a collection and interpretation phase of the monitoring data of a long time period (leachate quality and quantity, groundwater quality, etc.).

By this approach, we can try to answer technically the "Six Ws":

WHAT: Can we identify a conceptual model of the event including the fundamental elements of source-fate and transport-target? Which are the chemicals (heavy metals, ammonia, organics, etc.) that can affect the groundwater when they are released from the landfill to the environment?

WHERE: Can we identify the extent of the pollution in groundwater?

WHO: Can we identify the source of pollution beyond a reasonable doubt among the potential sources (industrial areas, agriculture activities, etc.)

WHEN: Can we identify when the pollution occurred and how long it lasted? 


\section{SCIENTIFIC APPROACH}

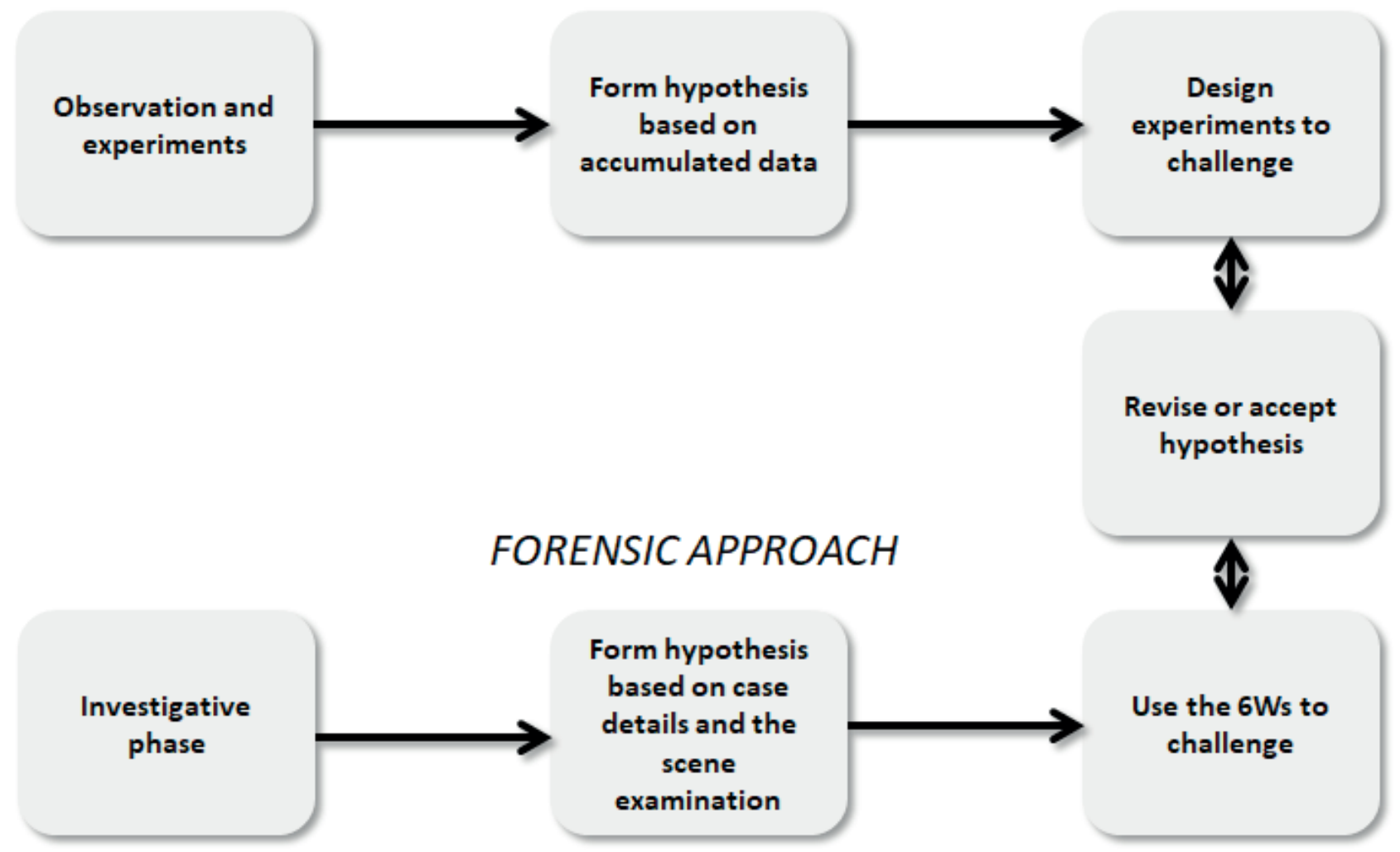

FIGURE 1: The similitude between the scientific and the forensic approach.

WHY: This is a matter for the judiciary to decide.

HOW: These are the processes that influence the fate and the transport of chemicals in the environment.

In summary, environmental forensics represents an important but often overlooked part of the criminal justice system. The breadth of different environmental crime types is such that a diverse range of approaches are required to investigate them. These multidisciplinary approaches originate from all science disciplines and bring together environmental science and forensic science techniques for the purposes of combating crimes to the environment.

Alberto Pivato, University of Padova (IT) alberto.pivato@unipd.it

Claire Gwinett, Staffordshire University (UK)

C.Gwinnett@staffs.ac.uk

GeorgeVarghese, NIT Calicut, Kozhikode (IN) gkv@nitc.ac.in

\section{REFERENCES}

McGee, Robert W. and Walter E. Block. 1994. Pollution Trading Permits as a form of market socialism and the search for a real market solution to Environmental Pollution. Fordham Environmental Law Journal 6: 51-77

Morrison, R. D and Murphy, B. L. 2005. Environmental Forensics: Contaminant Specific Guide. Academic Press. https://doi.org/10.1016/ B978-0-12-507751-4.X5021-6

Rusk, G. A. 1996. Environmental forensics: Technical support of complex environmental litigation. In Hazardous and Industrial Wastes: Proceedings of the Twenty-Eighth Mid-Atlantic Industrial and Hazardous Waste Conference, ed. A. Scott Weber, 760-774. Basel, Switzerland: Technomic Pub Co.

Nellemann, C. (Editor in Chief); Henriksen, R., Kreilhuber, A., Stewart, D., Kotsovou, M., Raxter, P., Mrema, E., and Barrat, S. (Eds). 2016. The Rise of Environmental Crime - A Growing Threat to Natural Resources Peace, Development and Security. A UNEPINTERPOL Rapid Response Assessment. United Nations Environment Programme and RHIPTO Rapid Response-Norwegian Center for Global Analyses, www.rhipto.org

Varghese, G. K. \& Babu J. Alappat (2012) National Green Tribunal Act: A Harbinger for the Development of Environmental Forensics in India?, Environmental Forensics, 13:3, 209-215, DOI: $10.1080 / 15275922.2012 .702330$ 